wounds on the neck. The scar tissue seemed healthy; no signs of any enlarged glands could be detected in the neck. On Aug. 25th the improvement was still maintained, and on Dec. 2nd the patient's condition continued unaltered.

The following are some points of interest in this case : 1. The delay in the appearance of the local reaction, which was first noticed when a condition of tolerance to 0.001 c.c. doses of tuberculin was apparently being established. 2. The appearance of swellings on the hands, which developed into abscesses. These might have been due to some latent tuberculous mischief and the thickening of the third metacarpal on the left hand may perhaps justify this conclusion. 3. Tolerance to tuberculin seemed to be readily established. 4. The rapid disappearance of the abscesses after the evacuaition of the pus, which in one case at least contained tubercle bacilli. 5. No medical or general treatment beyond that which has been recorded was adopted.

Merthyr Tydfil.

\section{SUBMUCOUS FIBROID TUMOUR OF THE ANTERIOR LIP OF THE UTERUS.}

BY SURgeoN-MaJor H. P. DIMMOCK, I.M.S., L.R.C.P. LOND., M.R.C.S. Ling.,

ghysiclan to the bat, Mothtbal and PETIT hospitals; PROFESSOR OF MODIHERY, GRANT MEDICAL COLLEGE ETC.

A HrNDoo WoMAx aged thirty-eight years was admitted into the Motlibai Hospital on March 4th with a tumour of large size, extending from the vulvæ. The patient could give no account of the development of the tumour, having become conscious of its presence only the day before I saw her. She stated that for the past three years or so she had suffered from a profuse leucorrhoal discharge, pain in the hypogastrium and back, constipation with a feeling of weight about the rectum and frequency and sometimes difficulty of micturition, with a burning sensation during the act. Menstruation had sometimes been painful and always excessive, lasting for five or six days, and it had been more so during the last three years, occurring at regular intervals. Two or three times during the intervals she had passed dark clots of blood. During the act of defecation she had felt as if there was "something in the abdomen which wanted to come away." . Lately she had been experiencing pains in the pelvic region, which radiated all over, and had also felt a hard ball in the hypogastrium, which after a while would disappear with a rolling movement. During the last few months her abdomen had seemed to increase in size, the breasts were hard and painful and she had gradually lost flesh. There was also a constant sen sation of nausea and sometimes she would vomit all her food. During the three days before consulting me she had fever preceded by chills and rigors of daily occurrence. The day before I saw her she had much pain in the back and hypogastrium, and the pain occurred at regular intervals, was of a bearing-down character and for about two hours was most violent, shooting down the legs and up the lumbar region, until at last a large fleshy mass was extruded per vaginam during the night and was followed by a watery discharge Some relatives who were attending to her tried to pull the tumour away, but finding that it was firmly attached they became alarmed and left her alone until the morning when they brought her to the hospital. Since the expulsion of the mass she had felt a little relief, but she complained much of a dragging. sensation and of inability to pass urine. The patient had suffered from ague and bronchitis six years previously, but otherwise had enjoyed good health until two years ago, when she began to lose flesh. Her husband died of dysentery eleven years before. She had never had any children. She was in a fair condition of body but was anæmic. Her temperature was $99.4^{\circ} \mathrm{F}$; the pulse was 108 and small. The respiration was hurried, and the tongue was pale and coated in the centre. The patient seemed to be somewhat exhausted, the skin was eold and clammy, and there was a large tumour hanging outside the vulva. The tumour was hard and conical in hape, being covered by thick mucous membrane, attached by a slender pedicle, and exuded. a watery and somewhat tenacious discharge. Its length was eight and a quarter inches, and its circumference at the thickest part was ten inches. After a stimulant had been administered and she had been given a vaginal douche the tumour was carefully examined, and it was then found that the pedicle was twisted and that with it there was some torsion of the cervix uteri, so that the os was occluded and hidden. The cervix was low down and, the sound having been passed, the uterus was found to be somewhat large and its cavity elongated, but beyond the prolapse there was not much displacement. The pedicle was about an inch and a half long, being cord-like and about oneeighth of an inch in diameter. The patient was immediately prepared for operation, the parts being well washed with warm antiseptic lotions and the urine was drawn off. As she was very excitable and unmanageable on account of the tenderness of the parts she was given chloroform. The pedicle was simply ligatured and the tumour cut away. The stump and upper part of the vagina were then insufflated with iodoform, a plug of lint which had been soaked in a lotion of perchloride of mercury ( 1 in 2000) was placed in the vulva and the patient was put to bed. She was restored to comfort and health. The next day the patient felt great relief; all the pain and dragging sensation had left her. On examination with the speculum the anterior lip of the cervix had become inverted, so that the stump and the ligature were quite inside the cervical canal, about half an inch away from the restored external os. Evidently the anterior lip of the cervix had been greatly stretched and the site of origin of the tumour had been from its inner surface. The tumour, on further examination and section, was found to be hard and composed of fibrous tissue in a state of partial fatty degeneration in parts. It was not traversed by any large bloodvessels, but was covered by a thick mucous membrane, which was fairly vascular. On pressure the cut surface exuded serous discharge.

Remarks. - This is the second tumour of the same kind which has been admitted into this hospital during the past three months. The first one occurred in an aged Parsee woman and was reported to the Grant College Medical Society by Dr. R. N. Khory. It was in a gangrenous state and had been so for days, and the patient was moribund from systemic septicæmia, of which she died within forty-eight hours of admission. The above case is interesting from its peculiar history, for there does not seem to have been much discomfort and the tumour never descended into the pelvis, but had a tendency to float up into the epigastric region. The miniature labour, too, is very graphic. It was, moreover, large for a submucous fibroid.

Bombay.

\section{A FATAL CASE OF \\ URAMIC COMA OCCURRING AT THE TERMINATION OF THE SECOND STAGE OF LABOUR.}

\section{BY EDGAR SWINDELLS, L.R.C.P.LOND., M.R.C.S. ENG.}

THE patient was a married woman aged forty years. About eight years ago, immediately after a confinement, she had an attack of hemiplegia. She was unconscious for an hour. On consciousness returning she had facial paralysis (left side), loss of speech and paralysis of the right arm and leg. These paralyses, with the exception of that of speech, disappeared. About eighteen months ago I attended her in a premature labour. She had no bad symptoms and made an uninterrupted recovery. There was no history of syphilis or alcoholism. On March 21st of the present year she was attended by my colleague, Mr. Alfred Huntsman, who has kindly furnished me with the following notes: "On March 21st I was called to see Mrs. _-, who was stated to have fallen down in a fit in the garden. On my arrival I found her seated in a chair in the garden, 'just coming to,' as her friends said. After examining her I asked her a few questions, but receiving no answer, I was informed by the friends that she was dumb, having had a like attack some years ago, which left her speechless. She is a stout woman, of about thirtysix or thirty-eight years of age and is advanced in pregnancy about five months. When I first saw her the face was flushed and the mouth covered with froth; the breathing was stertorous and there were rhythmical movements of the arms and hands. These symptoms, however, were passing off when $I$ arrived and in a few minutes she regained consciousness. Her pulse was slightly over 80 and with a good deal of tension. The heart was slightly hypertrophied, 